\title{
Precancerous Gastric Disease
}

H. MARVIN POLLARD, M.D.*

T $N$ THE DEVELOPMTNT of this particular subject, two aspects are I emphasized: first, the morphologie changes present in the stomach and their precancerous features, and second, the environmental or hereditary features that may go along with the development of this condition.

\section{MORPHOLOGIC FEATURES}

\section{Mucosal Atrophy and Achlorhydria}

The olrl concept of the abnormal mucosa has really not been improved upon. Sir Arthur Hurst and others referred to the abnormal mueosa, the achlorhydria, the atrophie change. Studies have continued along that line in an effort to determine whether that atrophic change is there preceding the gastric carcinoma or whother the atrophic change and the achlorhydria may go along with the development of the gastric carcinoma and cren be accentuated afterward.

Many studies have been done attempting to determine the degree of achlorhydria in patients with either a gastrie polyp or a gastric carcinoma. There is undoubtedly a high incidence of achlorhydria in gastric carcinoma. In our own experience, complete achlorhydria was present in 65 per cent, an additional 20 per cent had hypoaeidity, and the remainder had normal acidity. Therefore, gastric carcinoma is compatible with some degree of acidity. There is, howcrer, some alteration in the acid-secreting cells in association with the development of gastric carcinoma. It may be an abnomal mucosa that merely goes along with an abnomal growth process, or it may precele such. There is some evidence suggesting the development of carcinoma in the presence of a normal degree of acidity with achlorhydria developing at a later late.

Likewise, there is ovidence that in the presence of a gastric carcinoma there may be an atrophic change in the gastric mucosa, and as the disease progrosses the degree of atrophy increases. It is generally believed that the achlorhydria and the atrophic gastritis are merely manifestations of an abnormal mucosa upon

*Professor of Internal Medieine, University of Michigan, Ann Arbor, Mich.

Presented at the Pepti: Tlecr Symposium, Louisiana State Tnirersity, Nov. 1. 1958. 


\section{Pollard}

which a carcinoma develops and that they do not necessarily precede the development of the gastric carcinoma. Therefore, whether the sequence. was atrophy and or achlorhydria first, followed by the gastric carcinoma, is undecided. This indecision does not establish any etiologic concept for gastric carcinoma; it merely indicates that more has to be done along such lines in order to detexmine why snch individuals develop almormal mucosa upon which such transition may take place.

\section{Gastrie Polyp}

The gastric polyp for many years has been looked upou as a precursor. Whether or not it is truly precancerous or whether there are two distinet types-morely benigh polyps, and cancerous polyps-is not established. "There are those who believe that benign gastric and colonic polyps iever develop into careinoma. Gastrie polyps in observations extending over a period of nine or ten years have shown no exidence of malignant change. In all probabilitiy there are many benign polyps that never become eaucerous. However, there is reason to conelude that a small percentage probahly undergo transition to cancer.: The prineipal problem revolves around the initial diagnosis. The clinical inability to make the differental diagnosis enfores polypectomy because we cannof determine whether the polyp is benign or malignaint.

It has been conelusively demonstrated by Mandred Comfort that in individuals with gastric polyps then coexists an excedingly high incidence of achlorhydria. Therefore, here again there is some mucosal abnormality, perhaps atrophy, with associated seeretory suppression; in addition, a polyp exists or develops in that abnormal mueosa: It is suggested that in the background there exists some factor producing such abnomality that could bring about the three features of atrophy, secretory suppression, and polypoid change.

\section{Pernicious Anemia}

In patients with pernicious anemia there is necessarily a concomitant, eausal, or resultant achlorhydria. Some young individuals with early pernicions anemia may have a small amount of free hydroehloric acid; in general, however, any patient who has pernicious anemia will not have free hydrochloric acid. Studies on such individuals indicatas them to be increased gastric cancer 


\section{Precancerous Gastric Disease}

risks. The oceurrence of gastric carcinoma is probably twelve times more frequent than among the general population. Figures based on follow-up studies by $x$-ray at postmortem are confirmatory. Here again is abnormal gastric mncosa manifest in achlorhydria and atrophic changes, and the frequent development of either carcinoma or a polyp.

\section{Gastric Ulcer}

The presence of a gastric uleer is also an indication of abnormal mucosa. A debate has always revolved about whether a gastric ulcer may undergo malignant transition. That a few ulcers become malignant does not convey much significanee to the real issue.

The management of a patient with a gastric ulcer depends on whether or not the uleer is benign or malignant when first observed. The differential diagnosis can and should be established within a matter of a few weeks or, at the most, months, settling the issue at that time and not ereating concern as to whether or not this lesion may undergo transition to malignancy. It is my contention that an uleer develops in a gastric carcinoma and not the reverse. Cnless one has the opportunity to observe gastroscopically a earcinoma and later visualize an uleer developing in that same area, or vice rersa, there cannot be conclusiveness. While the controversy persists, the reports on benign lesions becoming malignant diminish and the problem has truly resolved into whether or not a lesion was malignant in the first place.

Comment. All of the morphologic changes I have mentioned have significance in developing the thesis that abnormal mucosa oceurs upon which a gastric carcinoma may develop. We still have a long way to go in knowing what that abnormality is, how long it must be present, and them bow long the gastric carcinoma takes to develop.

\section{ENYIRONMENTAL AND HEREDITARY FEATURES}

\section{Geographic Incidence}

The envirommental and hereditary features constitute a different aspect of this whole coneern. Geographic differences have heen studied intensively in recent ycars, with the conclusion that a geographic incidencenvariation exists for gastric carcinoma. This is included in discussing precancerous gastric disease becanse knowledge of what is going on in the different geographic areas may indicate some factor that is common to a group of individuals; 


\section{Pollard}

an environment, diet, or radiation exposure that predisposes that population segment to the development of a gastric carcinoma.

In a stndy of the southerm section of the country (Texas) as compared with a mid-northwestem area (Michigan), a greater incidenee of gastric carcinoma in onr colder climate. was foum as compared with the warmer elimate. (The two major studies were done in Dallas, Texas, and in Detroit, Michigan.). This distinet differcnce has been present year after year; it is not just bappenstance. In. Japan the incidence of gastric careinoma is almost twice that in this comtry: About 37 per 100,000 individuals in Japan have a gastric carcinoma, whereas the average in the United States is around 18 or 20. Among the Japanese residing in Hawaii and in Los Angeles, the incidence of gastric eareinoma is higher in the native-born than in the Hawailan-born or American-born Japanese. Tet in all three locations the Japanose have a higher incidence of gastivic carcinoma than the white population of the Cnited States. So here is some racial tendency modified by some other factor. Whether it is completely hereditary, racial, or the result of a change in dietary habits is debated; the latter is most often indicted. Other comparative mortality studies have been done in the Netherlands and England. In England the incidence of gastric careinoma is distinetly higher than in the Scandinavian countries. Whether or not that is dae to difference in diet actally has not as yet been established. We do not yet know whether it is the type of food or whether it is the type of onvironmont. We merely have made observations that permit speculation on available information. There is, however, something of significance that creates the difference in incidence of gastric careinoma in comparable areas.

One pleasing feature about the incidence of gastric carcinoma in this country is the fact that it is definitely decreasing. The United States Public Health Service has analyzed the incidence of gastric carcinoma in the Detroit hospitals, for example, going back fifteen years. Within recent years, a definite decrease in the incidence of gastrie carcinoma is evident in that community. The change is not explained. It can hardly be merely an improved ingestion of vitamins or more beef.

\section{Age and Sex}

From the standpoint of age, gastric carcinoma has of course been reported in youth, but the curvo ascends straight, without 


\section{Precancerous Gastric Disease}

leveling off at any age segment as it may in other diseases. One might speculate, therefore, whether something is injected into our life that is the carcmogenic agent. The actual incidence mas depend upon the amount of carcinogen injected over a long period of time, thereby producing the disease in a certain person; not injecting that amonnt permits the escape of another person.

Interestingly enough, a significant sex-related difference exists in the sites of carcinoma in the gastrointestinal tract. The incidence of carcinoma in the upper digestive tract is much higher in males over females. In the pharym, the esophagus, and stomach, the incidence of carcinoma is much higher in the male than it is in the femalo. As one descends the intestinal tract to the colon, an equalization for sexes is approached.

\section{Blood Group}

There have been observations indicating a rex convincing relationship of the blood group to the incidence of gastric carcinoma. There has been some emphasis made on lesions in the lower part of the stomach being more common in one blood group. This may indicate a predisposing factor.

\section{Heredity}

There are two conflicting reports on heredity. The Mimnesota group decided that there was no hereditary component in the incidence of gastric carcinoma. In the Netherlands it was concluded that the incidence of gastric carcinoma in the relatiros of patients with gastric carcinoma was four times greater than in the nomrelative group. Carcinoma of other organs in this group of relatives had $n$ greater incidence than in the average population.

Commen. Our geneticist feels that there is probably no proved relationship or proved increased incidenee from the environmental standpoint. Sociologically, it is true that the urban people have more gastric carcinoma than those residing in rural countries. Unmarried women and unmarried men have less gastric carcinoma than married persons. There are various features that seem to have some, but indefinite, bearing.

\section{PERIOD OF DEVELOPMENT}

Great interest has been focused on the length of time a gastric carcinoma takes to develop. There is evidence indicating that some gastric carcinomas may have a long quiescent existence. A mass 


\section{Pollard}

survey for gastric carciuoma on individuals 40 years of age and older, entering the Johns Hopkins Outpatient Department was conducted. From this group were selected 23 individuals with early defects in their stomachs ideally domonstrable by x-ray. Morgan personally followed that group for three years, and in that period there was very little change in the size of lesion. He did not pursue it beyond that time because of lack of funds and ontside interest. That he did not is regrettable, for we have no present knowledge of how long it takes a car cinoma to develop.

We may someday find some carcinogenic agent in our environment that has been present for a long period of time. The carcinoma itself may be present for a long time, and hence we may have an ample interval of time during which we could make the diagnosis. The hope at the present time is to disever that "something" which infuences the development of a gastric carcinoma after the diagnosis has been made. Certainly, surgery, at the present time the only curative approach, is not the ideal. Perhaps by utilizing some of the precursor lesions, some of the abnormal cells, some of the factors that we do know, admitting that this knowledge is modest, we can hope that over a period of time more work will be stimulated to be done on this subject and that someday we will have that necessary information about the development of this discase and, thence, its adequate management. 